\title{
Gender Ideology on Marriage in Contemporary Vietnam
}

\author{
Hien Thi Nguyen ${ }^{1}$, Lan Anh Hoang \\ The University of Melbourne
}

\begin{abstract}
This paper examines how conservative gender ideology affects Vietnamese men's and women's belief in marriage with a focus on the importance of marriage to their personhood and aspirations for ideal marital partners. Since marriage is a both legal and social recognition for the foundation and maintenance of families in a society, studying gender ideology on marriage helps to identify differences in men's and women's perspectives over marriage and how those views can reflect gender equality in the domestic sphere. The data on which this paper is based are part of a larger research project, namely "Understanding Gender and Marriage Ideology in Contemporary Vietnam" which was conducted in 2015. The results of the study indicate that marriage is still highly important to both Vietnamese men and women. Marriage is not only a social recognition regarding people's individual achievements and gender identities but also a type of economic investment (in children) for their old age. In relation to marriage aspirations, Vietnamese people still base on genderrole ideology, which highlights men's and women's distinctive roles in familial life, to select their marital partners. The persistence of Confucianism in Vietnamese society is the main source for Vietnamese people to set up criteria for their ideal partners.
\end{abstract}

Keywords: Gender, Gender Ideology, Marriage, Marriage Aspirations

\section{Introduction}

Marriage, as Becker (1981) defines, is a tool for each individual to realize his/her marital purposes in terms of reproduction and production. In this sense, people engage in marriage because they desire for stabilizing their lives and cooperate together in an institution to produce assets for their survival as well as to fulfill their reproductive function (bearing children to reproduce the labour force). However, from the viewpoint of Max Weber, marriage is more relevant to sexuality, i.e., people marry each other because they need to satisfy their sexual needs. In the past, marriage used to be a tool to restraint sexual freedom of women in patriarchal societies or of men in matriarchal ones. After that, in order to strengthen that patriarchal or matriarchal power, marriage conveys a larger meaning when it enables men or women to form and maintain their kinship groups and it is the basis

\footnotetext{
${ }^{1}$ nguyent5@student.unimelb.edu.au
} 
to determine property right for children (Hill, 2012). Nonetheless, if viewing people's purposes of marriage only in terms of material aspect, it is not totally accurate because marriage also has emotional meaning, in which, love is often the most common justification for marriage (Liu, 2008; Maslow, 1954). From legal perspective, lawyers define marriage as partnership which is maintained by legal recognition of authorities (Smith, 1990). The institutions of marriage are families or "gender factories", in which, human beings create and sustain their identities as men and women (Berk, 1985). In other words, the institutions of marriage are the places where femininities and masculinities are founded, reproduced and sustained in line with the existing social and cultural norms of a certain society. Therefore, it is very informative when studying gender in the institutions of marriage as gender relations are often most obvious in the domestic life, specifically, the relations between two genders (male and female).

\section{Gender ideology and marriage aspirations in the world}

According to human mate selection theory, femininity and masculinity concern both the biological and social characteristics that men and women consider in selecting their potential partners (Cunningham, 1986; Cunningham, 1990; Eagly \& Wood, 1999; Kenrick, 1994; Shoemake, 2007). Men and women have specific expectations for their partners to meet their personal interests and social requirements. Biologically, western ideals about femininity are linked to women's physical beauty represented by large eyes (neonate), a big smile (expressive), prominent cheekbones and a large chin (maturity) (Cunningham, 1986; Cunningham, 1990) while masculinity is associated with physical strength, genetic predisposition to aggression and sexual drives (Connell \& Connell, 2005). From a social perspective, femininity is defined as gentleness, empathy, sensitivity, dependence, passivity and weakness while masculinity should be courageous, independent, assertive, active and unemotional (Connell \& Connell, 2005; Stoller, 1984). Buss and Barnes (1986) indicate that women select their male partners based on men's power (earning capacity and higher education), which is more associated with social masculinities while men tend to choose their female partners based on 
their physical attractiveness (beauty), which is more associated with biological femininities. However, Kenrick and his colleagues (1993) argue that both men and women become more selective in the highest relationship investment level (marriage). Their mate selection is not only based on physical attractiveness (mainly done by men rather than women) but also includes other social criteria such as earning capacity, education (men), understanding, kindness (women) (Kenrick et al. 1990).

Nonetheless, the traits of femininity and masculinity are fluid as they adjust over time due to a shift in gender norms mainly caused by cultural changes (Schebert \& Wagner, 1975; Southern \& Plant, 1974; Stewart \& Healy, 1989). Additionally, attitudes towards femininity and masculinity do not totally depend on the gender belief system but also individuals' self-conceptions, which express their awareness and adaptation of the gender norms existing in their living context (Smith et al., 1999). Furthermore, different cultures have their own gender belief systems regulating characteristics of femininity and masculinity (Triandis \& Suh, 2002). Therefore, in studying people's concepts of masculinity and femininity, researchers need to locate them in a specific culture and a gender belief system, which itself has been constructed and maintained by that culture.

\section{Gender ideology and marriage aspirations in Vietnam}

The literature on gender and marriage in Vietnam indicates that gender and marriage ideology have been historically constructed by Confucianism that originated from Chinese culture (Belanger, 2002; Gammeltoft, 1999; Guilmoto et al., 2009; Rydstrom, 1998). It was then maintained by the practice of Buddhism (Do \& Fu, 2010; Leshkowick, 2006) and recently reinforced by the socialist model (Guilmoto, 2012; Schuler et al., 2006; Zhang \& Locke, 2002). Sharing the same perspective as biological and essentialist theorists regarding gender, Confucianism assumes that men are naturally different from women based on the Yin-Yang theory, in which Yin is female and Yang is male (Louie, 2002). Yin and Yang is posited in a contrary relation; Yin represents dark, cold, lower, rest, inward and inhibitory characteristics or femininity while Yang is equivalent to bright, hot, 
upper, movement, outward and excitatory features or masculinity (Louie, 2002). Therefore, men and women cannot be the same and women must be inferior to men to live together harmoniously (Jamieson, 1993; Nguyen \& Harris, 2009).

Confucianism also treats women as passive and dependent objects who must be led by men in families. In gender relations, Confucian ideology emphasizes women's lower position to men through requiring them to fulfill three duties: respecting fathers before marriage, husbands after marriage and (elderly) sons after husband's death (Nguyen, 2013; Schuler et al., 2006). Moreover, women are tied with four virtues in behaviours including diligent work, morality, proper speech and modest manner/appearance (Nguyen, 2013; Schuler et al., 2006). In contrast, Confucian ideology highly appreciates men by rewarding them with leading and decision-making roles in both the domestic and public sphere (Luong, 2006). In exchange for those roles, men must fulfill the role of breadwinners who financially support the whole family and are responsible for continuing the family legacy, performing ancestor worship and taking care of their parents in old ages (Guilmoto, 2012). Thus, male privilege is prevalent in Vietnam, especially in the Northern and Central regions (Belanger \& Oanh, 2009; Guilmoto, 2009; Guilmoto, 2012; Guilmoto, Hoang, \& Ngo, 2009). As a result, marriage tends to become the top priority for both men and women when they reach marriageable age, normally from 18 for women and 20 for men as stipulated by Marriage and Family Law in Vietnam (Williams, 2009).

Another force that has indirectly sustained conservative gender beliefs in marriage in Vietnam is the practice of Buddhism. Though Buddhism does not directly discriminate women like Confucianism, Buddhist concept of destiny is strongly associated with women's low position compared to men (Leshkowick, 2006). Buddhism states that each human being has his/her own destiny (innate fate) and talent (individual capacity). People can take their talents off to change their destinies. Nonetheless, that ideology applies to men and women differently. Men are encouraged to make use of all their efforts and intelligence toimprove their destiny, while women are assumed to face lots of constraints to succeed in changing their fate. Leshkowick (2006) indicates that the combination of Buddhism and 
Confucianism has tied women to poor fates, low positions and much less power in both familial and social lives.

Moreover, the Socialist Model has also strengthened conservative gender and marriage attitudes. Though men's and women's equal status in both public and domestic spheres has been legally recognized by the Government of Vietnam, the Communist Party has considered Confucianism as the country's main social and cultural values to guide and develop notions of women's roles in marital and familial lives (Schuler et al., 2006; Zhang \& Locke, 2002). In recent years, in line with creating favourable conditions for women to access higher education and participate in the labour market, the Vietnamese Government have also issued the legal legislations which indirectly discourage women from ignoring their roles as mothers and housewives (Schuler et al., 2006). For instance, the Government, through Vietnamese Women's Union (VWU) - a large socio-political organization of women established since the 1930s, have built and advocated for the high standards of Vietnamese femininity. VWU has launched a campaign of three criteria "study actively, work creatively, raise children well and build happy families" (Schuler et al., 2006, p. 386) to call for women's roles in preserving fine traditions of Vietnamese families. Indeed, there is no specific campaign to call for men's engagement in preserving those fine traditions or to highlight men's roles in promoting the development of the nation as well as families.

Vietnamese culture obviously supports a gender binary view towards masculinity and femininity, in which, women are symbols of beauty or weakness (for instance, they are called with the names of different types of flowers, fruit, the moon, and jewelries) while men represent power or strength (with the names of kings, dragons, strengths, large trees) (Nguyen \& Harris, 2009). "Vietnamese women have always been expected to be feminine, self-controlled, and virtuous, working and sacrificing themselves for the betterment of others", thus, womanhood of Vietnamese women is identified as "softness, chastity, determination and hard work" (Nguyen, 2013, p. 2). When selecting potential partners for marriage, Vietnamese men and women have been often based on social, cultural and social norms of femininity and masculinity to choose suitable ones. The candidates for marriage do not only meet 
their personal interests but more importantly meet social and parental expectations. Cultural and spiritual beliefs state that "a good woman of proper conduct and morals can bring happiness and good fortune to her family while and a bad woman brings tragedy and despair" (Nguyen \& Harris, 2009, pp. 132-133). Men, in contrast, are not tied to any duty except for the role of breadwinners and heirs to family legacy.

\section{Research data and methods}

This paper builds on a larger research titled "Understanding gender and marriage ideology in contemporary Vietnam" - a study focused on uncovering changes and continuity of Vietnamese people's beliefs in marriage, with a focus on their perceptions of the importance of marriage to Vietnamese personhood and marital infidelity in 2015. The results of the study have been used to develop the minor thesis, which is served for partial fulfillment of the requirements for a Master of Development Studies in the University of Melbourne. The data collection of the research was divided into two stages: (i) observations of real-life accounts and online discussions about marriage and family posted by members in the Revelation section of an online forum for Vietnamese women, Webtretho [literally in English, a website on children's matters]; (ii) in-depth interviews (IDIs) with 12 Webtretho's members who have been actively participating in giving comments and advice to the real-life accounts. For the purpose of this paper, I only draw on the results of IDIs with 6 men and 6 women $^{\mathrm{i}}$ who I purposefully selected to ensure a demographic diversity for the study. All IDIs were conducted between July and August 2015 via social media tools such as Skype, Facebook, Yahoo Messenger, Gmail or Viber.

The presentation section of research findings applies both analytical skills (critical thinking, data analysis) and compare and contrast skill to analyze and discuss the qualitative data. The section is structured in two parts: (i) meanings and purposes of marriage in men's and women's lives; (ii) Vietnamese people's aspirations for ideal marital partners. In this section, I pay particular attention to people's notions of femininity and masculinity as well as social expectations for men's and women's roles in marital and familial lives. 


\section{Research findings and discussions}

\section{Marriage as a defining feature of Vietnamese personhood}

In recent decades, researchers have found that marriage is in decline in a number of countries, which has been proven by falling rates of marriage, increasing percentages of delayed marriage, cohabitation, divorce and a larger percentage of the people who have never married (FengTian, 2013; Fussell \& Palloni, 2004; Jones, 2010; Jones \& Gubhaju, 2009; Kaufman \& Goldscheider, 2007; Mesch et al., 2005). Nonetheless, in the East and Southeast Asian countries where the kinship system remains prominent, marriage is still a universal phenomenon (Williams, 2009; Williams \& Guest, 2005) although delay in marriage, higher rates of divorce, singleness and cohabitation have also been on the rise (Jones, 2005; Jones, 2004).

In my IDIs with 12 men and women from Webtretho, the question "what do you think if a woman/man does not get married?" elicited almost identical response: it is strange because everyone must get married. That response is similar to the conclusion made by Williams and Guest (2005) and Williams (2009) that marriage is central to Vietnamese people's lives. Importance of marriage in Vietnamese personhood has been historically influenced by Confucianism and Buddhism, in which, Vietnamese people's attitudes toward marriage are both spiritually and culturally embedded. Spiritual beliefs mainly originate from Buddhism, in which, concepts of "luân hồi" (samsara) and "đầu thai" (reincarnation) have been highly influential among Vietnamese people (Jayakody \& Vu, 2012). It is believed that a man and a woman are brought together by a "nhân duyên vọ" chồng" (predestined affinity), i.e., their marital union has been decided by "duyên và nơ" (fate and conjugal debt) carried on from the previous life.

This was summed up succinctly by 38 -year-old Dzung:

"You cannot avoid marriage once your predestined spouse has been found"

(Dzung, male, 38 years old, Czech Republic). In Confucian ideology, marriage enables people to fulfill filial piety, which includes but is not limited to a child's respect, responsibilities and obligations to his or her parents (Sung, 1995). In relation to marriage, filial piety is about making parents happy and proud as well as sustaining the continuity of the family lineage 
(Belanger, 2004; Williams, 2009). Therefore, when a man or woman does not get married once she/he reaches marriageable ages, she/he is considered irresponsible and undutiful to his/her parents. One's singlehood undermines not only his reputation and social status but also the family's symbolic capital.

"If you think of your parents, you should get married and have your own family. Parents will never have peace in their mind if you stay single. Moreover, they will be also affected by the bad rumours that you are abnormal in some aspects"

(Luong, female, 29 years old, Hanoi)

In terms of the continuity of the family, filial piety refers to men's responsibility for getting married and bearing sons as only men and sons are recognized the official heirs to the family's legacy while women and girls are regarded as the outsiders, belonging to their husbands' families when they are married (Williams, 2009). Therefore, it is reasonable to assume that men would have higher demand for sons after marriage than women. Nonetheless, in my interviews with twelve participants, I found out that women wanted sons even much more than men as they feared that their positions in their husbands' families would be highly threatened if they could not fulfill their reproductive role 'satisfactorily'. In this sense, men's responsibility for fulfillment of filial piety is passed off to women, who are often condemned and disdained by both in-laws and relatives, even their husbands and communities if they cannot bear sons. It becomes a paradox when Vietnamese women have leaned on the "son preference" system to reinforce their positions in their in-law families. Gender inequalities persisting in Vietnamese society has rendered women's dependency on their husbands and even in-laws for economic support. In their old ages, that dependency is passed to their sons, which is the main reason why women prefer sons to girls. Although women are aware of their subordinate positions in families as well as social bias toward them and girl children, they tend not to take any active action to change their inferior statuses in families but maintain that inequality. They even do not want to bear girls as “...women and girls in Vietnam are too miserable and disadvantaged; I don't like my kid (girl) to suffer from that discrimination..."

(Luong, female, 29 years old, Hanoi) 
For a conservative society like Vietnam where the cohabitation of married couples is stigmatised marriage is the only appropriate institutional context for childbearing. Meanwhile, childbearing is also regarded as a mandatory, natural or even compulsory form of gender performance. Firstly, the perception that childbearing is "thiên chúc của phu nũ." (a natural vocation of woman) and a natural function of a man and woman to survive as human beings has been commonly perceived by IDI respondents. That response has been also mentioned in recent studies about Vietnamese people's attitudes towards marriage, notably Williams and Guest (2005), Williams (2009) and Vu (2013). According to my respondents, childbearing is a benchmark to measure men's and women's responsibilities and devotion to families as well as the extent to which they care for partners' feelings.

“...It is unacceptable when a woman does not want to bear a child (except for her health problems). If she does not want, she is selfish, only living for herself, not for others..."

(Huy, male, 31 years old, Hanoi)

"If my husband does not want to have children, he is not an ideal one in my eye as his desire for kids refers that he is keen on marriage, care for his families and me..."

(Suong, female, 25 years old, Hanoi) From economic aspect, childbearing is "economic stability" for men, and especially an "economic investment" for both men and women, from which they can gain benefits in their old ages. Marriage becomes a motive for men rather than women for their personal development, particularly in career promotion and income generation. The notion of "có an cu thi mới lạc nghiệp" (a rolling stone gathers no moss) is often taught by Vietnamese old generations to younger ones to emphasize the importance of marriage and has been highly supported by male respondents of IDIs. What the old saying implies is that only when a man is stabilized with a family, will he be able to strive for his economic development and career promotion. Meanwhile, economic investment for women lies in an implication that they look for economic security from their marital partners after marriage. Therefore, marriage is a clever choice for women to ensure their economic safety 
and old-age protection. Haughton and Haughton (1995) and Gallup (1995) in their studies about son preference and economic value of children in Vietnam, assert that children are important to couple's lives after marriage, especially in terms of the economic aspect. Considering the current limited financial capacity of the Government of Vietnam in deploying a comprehensive social safety net for all its citizens in terms of social and health insurance, caring and financial support in old age still depend on children's provision (Gallup, 1995). That dependence has been reduced among middle- and upper-class population groups who are mainly secured by retired pension or accumulated assets during their lives. However, most of the population, especially the people living in rural and mountainous areas, which accounted for up to 65.4 percent of Vietnamese population (GSO, 2016) do not have stable jobs and are not covered by any sustainable insurance scheme. Thus, that large population composition needs their children's economic and caring provision when they get older.

Marriage also serves to validate one's status, social recognition and identity. In the IDIs, all of the male and female respondents reported that marriage was their primary personal objective as well as parents' and social expectations.

"I think when a person dies, she/he will wish to be closely linked with his/her family. Only family members (husband/wife and children) can sacrifice all for him/her. Parents cannot live forever with him/her while relatives, brothers, sisters, friends also have their own families to concern, thus, he/she has to marry to have his/her own families"

(Trang, female, 30 years old, Hanoi)

As claimed by Belanger (2004), Vietnamese men and women should be married before reaching the age of 35 and 30, respectively. Accordingly, marriage after those ages is supposedly too late and not good for bearing children. Moreover, marriage can bring men and women a sense of social conformity. Belanger (2004) in her work, Single and Childless Women of Vietnam: Contesting and Negotiating Female Identity indicates that Vietnamese women are recognized as completely "grown up" only after marriage and then becoming mothers. For those who are still 
single or childless, they are easily badly rumoured by their relatives, neighbours and acquaintances about their

"bad temper and selfishness, fussiness in choosing a spouse, unwillingness to fulfill their womanly natural functions, and even perhaps their sexual "abnormality" (Belanger 2004, p.96). In this study, respondents of in-depth interviews have expressed similar thoughts as identified by Belanger (2004):

"In Vietnamese society, a man or a woman, when reaching the marriageable age, needs to get married. For those who are still single I find them, to some extent, ...uhm...abnormal. It maybe because they are too independent or think in the ways different from others. However, living differently from others is really hard in Vietnam....people will gossip and question about him/her...whenever you go out or meet friends or relatives, the frequent question posted to you will be: when do you get married?"

(Chi, female, 27 years old, Hanoi).

The above-mentioned research evidence indicates that conservative gender ideology has clearly shown in people's beliefs in the institution of marriage. The following part of the paper on marriage aspirations will help to expose more how gender ideology have shaped the institution of marriage.

\section{Marriage aspirations for ideal marital partners}

This part focuses on examining Vietnamese people's perceptions of femininity versus masculinity in marital mate selection as well as their expectations for partners' gender roles in marital lives to identify how gender ideology has influenced the institution of marriage. Previous research, notably by Buss and Barnes (1986) and Cunningham (1986) about western attitudes toward mate selection for marriage, asserts that men have been more attracted by women's physical appearance or biological femininity in selecting potential partners. In contrast, women's selection for their marital partners is mainly based on men's education and earning capacity or social masculinity. As framed by a different culture and social belief system, Vietnamese men's and women's criteria for mate selection are somewhat different from western beliefs. In my interviews with both 
men and women, I found that physical attractiveness did not play a significant role in Vietnamese men's nor women's selection for marital partners but kindness, virtue, education, family background, moral integrity of women and earning capacity, understandings, family background and social status of men are much more important.

“...Physical appearance does not matter to me unless she is too ugly. I appreciate a woman with high morality..."

(Thiet, male, 32 years old, Hanoi)

“...I do not need a handsome husband... but (smile)...if he is good-looking,... it does matter...The most important criteria that a husband should have are his good earning capacity, good education and personality..."

(Luong, female 29 years old, Hanoi)

While all male and female respondents did not deny that they only married those they loved or at least had intimate feelings with, the foremost criterion influencing their mate selection is potential capacities of men and women in fulfilling their traditional gender roles. Most female respondents of IDIs and Webtretho's members appreciated men's potential for income generation. Men's earning capacity is interpreted as their good education, strong will, and clearly strategic plan for developing a career.

“...I need a husband who can perform his breadwinner role in all aspect of family life..."

(Trang, female, 30 years old, Hanoi)

“... like a man of work and he must have dream of becoming rich... This is the most important point. In addition, he should be well-educated, trusted, knowledgeable, intelligent, have sense of humour, understand and share with his partner...."

(Suong, female, 25 years old, Hanoi)

That women's main selection criterion for male marital partners is financial capacity indicates that Vietnamese men are still highly expected to keep and perform their gender role as breadwinners. This finding is in line with the research results indicated by Teerawichitchainan, Knodel, $\mathrm{Vu}$, and $\mathrm{Vu}$ (2010) when studying gender relations in Vietnam. 
On the contrary, in this study, men's criteria for mate selection are rather different from women's. As women are expected to perform gender roles as mothers and homemakers, men often pay attention to women's "vẻ đẹp nội tâm" (inside beauty), which is measured by the four virtues including diligent work, modest manner, proper speech and morality as regulated by Confucianism (Nguyen \& Harris, 2009; Nguyen, 2013) to select potential partners.

“...An ideal wife...uhm...as our ancestors' criteria ...diligent work, morality, proper speech and modest manner...She should be good at domestic science (cooking, cleaning, sewing, caring kids), ability of well dealing with internal and external affairs..."

(Hoa, male, 31 years old, Hanoi)

Women's diligent refers to their diligence to both domestic and professional work (Nguyen, 2013). At home, women should undertake all household tasks regardless of their difficulties with orderly manners and time effectiveness. At work, although women are not expected to be as successful as men in income earning and career development, they still should fulfill their assigned professional tasks well and contribute to family income. Women's modest manner is not about their physical beauty but how womanly they are (Schuler et al., 2006). If a woman is recognized for her modest manner, she should have clean, tidy and careful self-presentation to express self-respect and respect for others. Proper speech refers to women's capability of communicating to others (Nguyen, 2013). If a woman can speak well and has skills for articulating words with grace and tenderness, which can please the listeners, she will automatically attract a number of men. Men's final criterion for selection of female partners is morality. According to Nguyen (2013), this criterion is the most important factor for Vietnamese men to select an ideal wife. As Vietnamese women occupy different positions in familial lives, they are "rewarded" with the role of "morality keepers" for their whole families before and after marriage (Nguyen \& Harris, 2009). Women's morality is associated with their responsibilities as dutiful daughters before marriage and as devoted wives and caring mothers after marriage. Moreover, the central point of Vietnamese women's moral characteristics are their self-sacrifice and endurance, which are the two most 
recognized important factors to sustain their familial lives. In addition, in Vietnam the notion of women's morality is also highly attached with their fidelity in marriage as their chastity is not only their honour but their husbands' and in-laws'.

There have been some changes in men's gender ideology in selecting partners as several of the male respondents have not emphasized women's conservative gender roles as mothers and housekeepers. They also support their wives to have paid jobs, pursue their career and get promotions. More men have accepted that their wives can be better than them regarding education, earning capacity, knowledge, intelligence and work.

"Describe an ideal wife...it is not hard, it is my wife. She has good knowledge of her working fields and significant knowledge in others. She is well-educated, enough qualifications to work and dealing with the problems at work...lightsome, clever...intelligent, having sense of humor..." (Thiet, male, 32 years old, Hanoi)

However, all male and female respondents of IDIs shared similar viewpoints that the central role of women should still be at home as men cannot support or replace women's domestic roles. Male respondents did not deny that an increasing number of women have had better education, better jobs and higher income than men. Nonetheless, they cannot ignore family and childcare as their main responsibility is to "xây tổ ấm" (maintain family harmony and happiness). When I raised the question: "should women keep the breadwinning role and vice versa, should men keep homemaking role?" Most of the male and female respondents responded similarly that "they should not" as it would threaten the sustainability of families and spousal relations.

"...I do not support for the model of a woman who keep the breadwinning role and entrust all domestic work to her husband. A man is innately not as clever as a woman; therefore, he is impossible to take care of the family as well as a woman. I believe that despite how much a woman can earn, she still has to keep an eye on her family, domestic chores and childcare..."

(Chau, female, 31 years old, Thanh Hoa)

In Vietnamese people's gender ideology and practices, women's better earning capacity and career development than their husbands are potential risks to 
the stability of family. When men are inferior to their wives and cannot perform their financial provision role, their masculinity is easily hurt. Consequently, they will seek different measures to rescue their masculinity such as beating wives (Vu et al., 2014) or engaging in extra-marital relations Nguyen \& Harris (2009). Therefore, in order to avoid family conflicts, the women with better economic capacities must be very "clever" in behaving toward their husbands so as not to hurt their masculinity. If they show any superiority to their husbands because of her higher income or better job, their families will be at high danger of dissolution.

"...I do not oppose a woman who can earn more than her husband because at present, lots of women are well-educated and intelligent. However, if they want to maintain their families happily and sustainably, they must be very clever and intelligent in treating husbands and should never compare them with other men..."

(Tai, male, 28 years old, Hochiminh)

In asking about feasible solutions to sustain the institutions of marriage in a modern society where Vietnamese women's families and social statuses have been improved, both male and female respondents of IDIs stated that women should successfully fulfill all their roles as employers, domestic workers and mothers. That answer deeply expresses that Vietnamese people are endorsing a new form of gender ideology, which even more burdens women and sharpens gender inequality in society. Schuler et al. (2006) in her work on Constructions of Gender in Vietnam: In Pursuit of the 'Three Criteria' carries out a very detailed analysis on how triple roles have been constructed and advocated by different social and political forces, including Confucian culture, social norms, individual perspectives and even the Government of Vietnam. The advocacy of the Vietnamese Government over the past decades for women's active engagement in the labour market and in sustaining family happiness Schuler et al. (2006) have created higher standards for a model of "modern" Vietnamese women. It is notable that VWU, a socio-political entity representing Vietnamese women's rights and benefits, has played the central role in advocating for this type of gender inequality. Consequently, progresses in economic development and women's empowerment have not contributed to improving 
Vietnamese women's statuses but pushed them to a dilemma where they must decide between career and family.

${ }^{\mathrm{i}}$ The interviewees are all Vietnamese coming from different regions of Vietnam and belonging to different ethnicities (Kinh, Tay and Tho). Their ages range from 25 to 40 and are both married and unmarried. In particular, the respondents are doing different jobs such as housewives, teachers, businessmen, engineers, civil servants, clerks, human resource and marketing staff. Regarding educational/professional attainment, all the interviewees have completed general education. Several have got secondary professional or vocational diplomas. Others have bachelor or master degrees. In order to protect respondents' privacy as regulated by the ethical rules of the University of Melbourne, pseudonyms are used to all IDI respondents when analysing the study results. 


\section{References}

Becker, G. S. (1981). A Treatise on the Family. Cambridge: Harvard University Press.

Belanger, D. (2002). Son Preference in a Rural Village in North Vietnam. Studies in Family Planning, 33(4), 321-334.

Belanger, D. (2004). Single and Childless Women of Vietnam: Contesting and Negotiating Female Identity? In L. B. W. Drummond \& H. Rydstrom (Eds.), Gender Practices in Contemporary Vietnam. Singapore and Denmark: NUS Press.

Belanger, D., \& Oanh, K. T. H. (2009). Second-Trimester Abortions and SexSelection of Children in Hanoi, Vietnam. Population Studies, 63(2), 161 171.

Berk, S. F. (1985). The Gender Factory: The Appoitment of Work in American Households (S. F. Berk Ed. 18 ed.). New York: Plenum Press.

Bui, T. C., Markham, C. M., Ross, M., Williams, M. L., Beasley, R. P., Tran, L. T., . . . Le, T. N. (2012). Dimensions of Gender Relations and Reproductive Health Inequity Perceived by Female Undergraduate Students in the Mekong Delta of Vietnam: A Qualitative Exploration. Internationa Journal for Equity in Health, 11(63), 1-11.

Buss, D. M., \& Barnes, M. (1986). Preferences in Human Mate Selection. Journal of Personality and Social Psychology, 50(3), 559-570.

Connell, R. W., \& Connell, R. (2005). Masculinities (2 ed.). California, US: University of California Press.

Cunningham, M. R. (1986). Measuring the Physical in Physical Attractiveness: Quasi-Experiments on the Sociobiology of Female Facial Beauty. Journal of Personality and Social Psychology, 50(5), 925-935.

Cunningham, M. R. (1990). What Do Women Want? Facialmetric Assessment of Multiple Motives in the Perception of Male Facial Physical Attractiveness. Journal of Peronality and Social Psychology, 59(1), 61-72.

Do, M., \& Fu, H. (2010). Attitudes Toward Premarital Sex in Contemporay Vietnam: Findings from a National Survey. International Journal of Sexual Health, 22(2), 103-118.

Eagly, A. H., \& Wood, W. (1999). The Origins of Sex Differeces in Human Behaviour: Evolved Dispositions Versus Social Roles. American Psychologist, 54(6), 408-423.

FengTian, F. (2013). Transition to First Marriage in Reform-Era Urban China: The Persistent Effect of Education in a Period of Rapid Social Change. Popul Res Policy Rev, 32(4), 529-552. doi:10.1007/s1113-013-9272-y

Fussell, E., \& Palloni, A. (2004). Persistent Marriage Regimes in Changing Times. Journal of Marriage and Family, 66(5), 1201-1213.

Gallup, J. L. (1995). The Economic Value of Children in Vietnam. Retrieved from Hanoi, Vietnam:

Gammeltoft, T. (1999). Women's Bodies, Women Worries: Health and Family Planning in a Vietnamese Rural Commune. Surrey: Curzon. 
GSO. (2016). Report on First Six-Month Socio-Economic Development of Vietnam. Retrieved from http://viettimes.vn/dan-so-viet-nam-uoc-tinh-927trieu-nguoi-ty-le-that-nghiep-la-227-64198.html, Hanoi, Vietnam:

Guilmoto, C. Z. (2012). Son Preference, Sex Selection, and Kinship in Vietnam. Population and Development Review, 38(1), 31-54. doi:10.1111/j.17284457.2012.00471.x

Guilmoto, C. Z., Hoang, X., \& Ngo, V. T. (2009). Recent Increase in Sex Ratio at Birth in Vietnam. PLoS One, 4(2), 1-7.

Haughton, J., \& Haughton, D. (1995). Son Preference in Vietnam. Studies in Family Planning, 26(6), 325-337.

Hill, S. A. (2012). The Evolution of Families and Marriage Families: A Social Class Perspective (pp. 184). New York: SAGE Publications, Inc.

Jamieson, N. L. (1993). Understanding Vietnam. Berkeley, US: University of California Press.

Jayakody, R., \& Vu, T. H. (2012). Social Change and Marriage in Vietnam: From Social State to Market Reform. In R. Jayakody, A. Thornton, \& W. Axinn (Eds.), International Family Change: Ideational Perspectives (pp. 199-223). London: Routledge.

Jones, G. (2005). The "Flight from Marriage" in Southeast and East Asia. Journal of Comparative Family Studies, 36(1), 453-478.

Jones, G. W. (2004). Not "When to Marry' but "Whether to Marrry': The Changing Context of Marriage Decisions in East and Southeast Asia. In G. W. Jones \& K. Ramdas (Eds.), Untying the Knot: Ideal and Reality in Asian Marriage (pp. 3-56). Singapore: Asia Research Institute, National University of Singapore.

Jones, G. W. (2010). Changing Marriage Patterns in Asia. Retrieved from Singapore:

Jones, G. W., \& Gubhaju, B. (2009). Factors Influencing Changes in Mean Age at First Marriage and Proporitions never Marrying in the Low-Fertility Countries of East and Southeast Asia. Asian Population Studies, 5(3), 237265.

Kaufman, G., \& Goldscheider, F. (2007). Do Men "Need" a Spouse More than Women?: Perceptions of the Importace of Marriage for Men and Women. The Sociological Quarterly, 48(1), 29-46.

Kenrick, D. T. (1994). Evolutionary Social Psychology: From Sexual Selection to Social Cognition. In M. P. Zanna (Ed.), Advances in Experimental Social Psychology (Vol. 26, pp. 75-121). San Diego: Academic Press.

Kenrick, D. T., Groth, G. E., Sadalla, E. D., \& M.R.Trost. (1993). Integrating Evolutionary and Social Exchange Perspectives in Relationships: Effects of Gender, Self-Appraisal and Involvement Level on Mate Selection Criteria. Journal of Peronality and Social Psychology, 64(6), 951-969.

Kenrick, D. T., Sadalla, E. K., Groth, G., \& Trost, M. A. (1990). Evolution, Straits and the Stages of Human Courtship: Qualifying the Parental Investment Model. Journal of Personality, 58(1), 97-116. 
Leshkowick, A. M. (2006). Women, Buiddhist, Entrepreneur: Gender, Moral Values, and Class Anxiety in Late Socialist Vietnam. Journal of Vietnamese Studies, 1(1-2), 277-313.

Liu, X. (2008). Material vs. spiritual - A Novel Economics Perspective on Marriage and Divorce. the Journal of Socio-Economics, 37.

Louie, K. (2002). Theorising Chinese Masculinity: Society and Gender in China. London: Cambridge University Press

Luong, H. V. (2006). Structure, Practice, and History: Contemporary Athropological Research on Vietnam. Journal of Vietnamese Studies, 1(12), 371-409.

Maslow, A. (1954). Motivation and Personality. New York: Harper and Brothers.

Mesch, B. S., Singh, S., \& Casterline, J. B. (2005). Trends in the Timing of First Marriage among Men and Women in the Development World. Washington D.C: The National Academies.

Nguyen, K. L., \& Harris, J. D. (2009). Extramarital Relationships, Masculinity, and Gender Relations in Vietnam. Southeast Review of Asian Studies, 31(1), 127-142.

Nguyen, T. H. (2013). The Vietnamese Concept of a Feminine Ideal and the Images of Australian in Olga Masters' Stories. Gender Forum: An Internet Journal for Gender Studies, 1(45), 1-10.

Rydstrom, H. (1998). Embodying Morality: Girls' Socialization in a North Vietnamese Commune. Linkoping: Linkopig University.

Schebert, D. S., \& Wagner, M. E. (1975). A subcultural change of MMPI norms in the 1960s due to adolescent role confusion and glamorization of alienation. Journal of Abnormal Psychology, 84(4), 406-411.

Schuler, S. R., Hoang, T. A., Vu, S. H., Tran, H. M., Bui, T. T. M., \& Pham, V. T. (2006). Constructions of Gender in Vietnam: In Pursuit of the 'Three Criteria'. Culture, Health and Sexuality, 8(5), 383-394.

Shoemake, E. G. (2007). Human Mate Selection Theory: An Integrated Evolutionary and Social Approach. Journal of Scientific Psychology, 1(1), $35-42$.

Smith, B. A. (1990). The Partnership Theory of Marriage: A Borrowed Solutio Fails. Texas Law Review, 68.

Smith, C. J., Noll, J. A., \& Bryant, J. B. r. (1999). The Effect of Social Context on Gender Self-Concept. Sex Roles, 40(516), 449-512.

Southern, M. L., \& Plant, W. T. (1974). Decade differences in personality of junior college and university freshmen. Psychological Reports, 34, 383-388.

Stewart, A. J., \& Healy, J. M. (1989). Linking individual development and social changes. American Psychologist, 44(1), 30-42.

Stoller, R. J. (1984). Sex and Gender: The Development of Masculinity ad Femininity. London: Jarnac Books.

Sung, K.-t. (1995). Measures and Dimensions of Filial Piety in Korea. The Gerentologist, 35(2), 240-247. 
Teerawichitchainan, B., Knodel, J., Vu, M. L., \& Vu, T. H. (2010). Division of Household Labour in Vietnam: Cohort Trends and Regional Variations. Joural of Comparative Family Studies, 41(1), 57-85.

Triandis, H. C., \& Suh, E. M. (2002). Cultural Influences on Personality. Annual Review of Psychology, 53, 133-160.

Vu, S. H., Schuler, S., Hoang, T. A., \& Quach, T. (2014). Divorce in the Context of Domestic Violence Against Women in Vietnam. Cultural Health Sex, 16(6), 434-447.

Vu, T. T. (2013). Attitudes to Marriage of Young Married People in Vietnam. (PhD), Latrobe University, Melbourne, Australia.

Williams, L. (2009). Attitudes Toward Marriage in Northern Vietnam: What Qualitative Data Reveal about Variations across Gender, Generation, and Geography. J Pop Research, 26(4), 285-304.

Williams, L., \& Guest, M. P. (2005). Attitues Toward Marriage Among the Urban Middle-Class in Vietnam, Thailand ad Philippines. Journal of Comparative Family Studies, 36(2), 163-186.

Zhang, H., \& Locke, C. (2002). Contextualizing Reproductive Rights Challenges:

The Vietnam Situation. Women's Studies International Forum, 25(4), 443-453 